\title{
O SILÊNCIO COMO DISCURSO: O PROJETO DE LEI "ESCOLA SEM PARTIDO" E A INVISIBILIDADE DA JUVENTUDE LGBT NA LÓGICA DA MORDAÇA
}

\author{
Maria Eduarda Parizan Checa (PUC-SP - duda.checa@gmail.com) \\ Andrea Cristina Coelho Scisleski (- ascisleski@ yahoo.com.br)
}

\section{RESUMO}

Este artigo problematiza a interdição à cidadania da juventude LGBT a partir tanto da atual tramitação do PL (Projeto de Lei) "Escola sem Partido" na Câmara Municipal de Campo Grande - MS quanto das reverberações dos discursos que o permeiam em nível nacional. $\mathrm{O}$ PL tem como determinação a proibição da abordagem de temas como gênero e sexualidade nas escolas, com a justificativa de que tais temas marcariam uma postura "partidária" da escola, enquanto a mesma deveria ser politicamente neutra, deixando a abordagem de tais questões exclusivamente no âmbito familiar. Um dos questionamentos que o presente trabalho suscita é "Em um cenário em que a juventude LGBT é majoritariamente violentada por familiares e conhecidos (GRUPO GAY DA BAHIA, 2017), a escola, enquanto espaço de produção de cidadania, não deveria ser a esses jovens um espaço de proteção?" e mais: "Ao silenciar os temas que poderiam dar voz às eventuais violências sofridas por esses jovens, a escola não seria, ela mesma, um espaço violador?". Ao pensar, juntamente com Foucault (1999), o processo de produção de discursos em meio às relações de saber-poder que atravessam o atual cenário pós-golpe em que vivemos, entendemos que a proposta do PL de neutralidade do espaço escolar é defensora de uma escola que toma partido pela (re)produção da invisibilização da juventude LGBT a partir da proibição discursiva da mesma no espaço escolar. Em outras palavras, a obrigação do silêncio das questões de gênero e sexualidade na escola institui uma política não apenas de legitimação da violência sofrida por essa população, como também compõe parte de um cenário de desmonte de Políticas Públicas implicadas na visibilidade de populações marginalizadas, visando, sobretudo, formas capilares de extermínio das mesmas.

Palavras-chave: Juventude LGBT, Escola sem Partido, Discurso.

\section{SILENCE AS DISCOURSE: THE “ESCOLA SEM PARTIDO” LAW PROJECT AND THE INVISIBILITY OF LGBT YOUTH IN THE GAG LOGIC}

\begin{abstract}
This article problematizes the ban on the citizenship of LGBT youth from both the current process of the PL (Law Project) "School without party" in the City Hall of Campo Grande MS and the reverberations of the discourses that permeate it at the national level. The PL has as its goal the prohibition of addressing issues such as gender and sexuality in schools, with the justification that such themes would mark a "partisan" stance of the school, while it should be politically neutral, taking these topics as familly issues. One of the questions that the present work raises is "In a scenario where LGBT youth are mostly violated by family members and acquaintances (GRUPO GAY DA BAHIA, 2017), the school, as a space for the production of citizenship, should not be for these young people a space of protection?" and more: "By silencing the themes that could give voice to the violence suffered by these people, would not the school itself be a violating space?" Thinking with Foucault (1999) the process
\end{abstract}


of producing discourses in the midst of the relations of know-how that cross the current postcoup scenario in which we live, we understand that the PL's proposal of neutrality in school is a defender of a school that takes part in the (re)production of the LGBT youth's invisibility from the discursive prohibition of them in the school space. In other words, the obligation in silencing the issues of gender and sexuality in school institutes a policy not only to legitimize the violence suffered by this population, but it also constitutes part of a dismantling scenario of Public Policies implied in the visibility of marginalized populations, aiming, above all, capillary forms to exterminate them

Keywords: LGBT youth, School without party, Discourse.

\section{INTRODUÇÃO}

Este artigo é fruto do desenvolvimento da pesquisa de Iniciação Científica de uma das autoras, Maria Eduarda Parizan Checa (2017), cujos desdobramentos vinculam-se à pesquisa "Políticas Públicas para jovens em conflito com a lei: uma análise da rede de proteção e de segurança", coordenada pela outra autora, Andrea Cristina Coelho Scisleski (2017). Tais diálogos iniciaram-se com o intuito de problematizar as redes de proteção (que também podem ser de segurança) que se formam (ou não) a partir das Políticas Públicas voltadas à juventude LGBT no cenário de Campo Grande - MS, bem como sua articulação com as determinações legais nacionais ${ }^{1}$.

No entanto, no decorrer da pesquisa o PL (Projeto de Lei) "Escola sem Partido" que, dentre outras coisas, proíbe a discussão de temas como sexualidade e gênero nas escolas - e que será explanado adiante - foi aprovado em regime de urgência no município de Campo Grande - MS. A partir disso, o foco da investigação voltou-se à análise dos discursos que atravessam e são atravessados pelo PL, bem como sua relação com a (des)proteção da juventude LGBT nos espaços familiar e da escola, haja vista que esses espaços são (des)articulados no corpo do texto do PL em questão.

Atrelada a tal discussão está o cenário que se formou nos arredores (antes, durante e depois) do Golpe (vulgo impeachment) ocorrido no Brasil em 2016. Sob essa perspectiva, fez-se necessário trazer à tona os desdobramentos micropolíticos (GUATTARI; ROLNIK, 1999) que sustentaram e continuam sustentando o golpe enquanto acontecimento em sua materialidade discursiva. Isto é, naquilo que dele se espalha e que resvala - especialmente -

\footnotetext{
${ }^{1}$ Aqui o termo "determinações legais" se refere tanto a legislações, quanto a Projetos de Lei e outros acontecimentos que, de acordo com Agamben (2004), possuem "força-de-lei" no cenário atual. Ou seja, cuja emergência é determinada, sobretudo, por um teor autoritário-legal sobre a realidade, ainda que não se tratem de leis, de fato.
} 
em populações já marginalizadas pelo "estado de exceção" da democracia (AGAMBEN, 2004) que se tem vivenciado, como parece ser o caso da relação entre o PL "Escola sem Partido" e a (des)proteção da juventude LGBT.

Em síntese, o presente artigo objetiva, principalmente, problematizar a imposição do silêncio sobre a juventude LGBT a partir do trâmite do Projeto de Lei "Escola sem partido", bem como suas interferências na (des)proteção e na cidadania da juventude LGBT na cidade de Campo Grande - MS (onde a pesquisa foi realizada), e eventuais ressonâncias ${ }^{2}$.

Utilizando como método a análise do discurso foucaultiana, foi feita uma leitura do PL (Projeto de Lei) "Escola sem partido", sobretudo a partir de suas conexões discursivas com outros acontecimentos. Uma vez que, para Foucault (2008), a análise de um discurso não se dá apenas no esgotamento conceitual de um texto ou de um documento em si mesmo. A grande questão dela, enquanto método, é desdobrar o que constitui um discurso a partir de sua conectividade, ou seja, pela forma como ele se relaciona para além do texto e significa a si mesmo a partir das relações que o extrapolam.

Assim, esta pesquisa caracterizou-se como documental e buscou analisar o(s) discurso(s) presente(s) no PL "Escola sem partido" a partir, também, da leitura de outros documentos e acontecimentos com os quais esse se conecta, estabelecendo assim um diálogo entre esses e as leituras teóricas de Michel Foucault, Giorgio Agamben, Gilles Deleuze, Félix Guattari e outrxs ${ }^{3}$ que aqui auxiliaram a (des)pensar a juventude LGBT, o contexto do Golpe de 2016 e os desdobramentos relacionais nas e com as Políticas Públicas produzidas nesse contexto.

\section{Família, escola e as tecnologias de governo da(s) sexualidade(s)}

De acordo com o Plano Nacional de Cidadania e Direitos Humanos de LGBT (2009), é dever do Estado, como democrático, implementar Políticas Públicas que garantam cidadania, igualdade de direitos e proteção à população LGBT, pois faz parte do processo de democratização do Estado a inserção dessa população como cidadãos de direito e, por isso, o

\footnotetext{
${ }^{2}$ Referimo-nos às conexões discursivas que ligam o cenário da juventude LGBT campo-grandense ao restante do país face ao contexto político do pós-golpe que vivenciamos.

3 Ao longo do texto, procurou-se utilizar a linguagem gendrada, substituindo os pronomes masculinos e femininos ("o" e "a") pela letra "x" nas palavras. Pois, ao considerar a pesquisa e a escrita como atos políticos, torna-se fundamental subverter - a partir do que nela é minuncioso - a hegemonia do pronome masculino quando esse se refere aos entes masculinos e femininos. O "x" é, assim, uma escolha que abarca ambos os gêneros e torna o fluxo da escrita mais coerente à proposta da pesquisa.
} 
Plano tem suas diretrizes pautadas na Constituição Federal em vigor. Dentro dessas determinações, está a "Prevenção e enfrentamento da vulnerabilidade social de crianças e jovens em razão da orientação sexual e identidade de gênero" (BRASIL, 2009, p.15).

Ressaltamos a prevenção e o enfrentamento da violência dirigida a jovens LGBT como pauta da agenda de Direitos Humanos no Brasil, pois de acordo com o Relatório de Violência Homofóbica mais recente, emitido pelo Grupo Gay da Bahia (2017), o maior índice de morte violenta (homicídio e suicídio) de pessoas LGBT no Brasil corresponde à juventude.

Além disso, em relação a esses, ganha destaque o fato de que grande parte das mortes está relacionada a casos de violência intrafamiliar, ou de suicídio vinculado à rejeição familiar exposta pela vítima, como no seguinte caso - Trazido pelo Grupo Gay da Bahia - em que um jovem gay de 16 anos do Ceará foi morto durante o que as autoridades chamaram de um “conflito familiar" (2017: 15): "A polícia não informou qual parente teria agredido o jovem. Típica omissão informativa homofóbica que contribui para a manutenção do complô do silêncio contra o amor que não ousava dizer o nome" (GRUPO GAY DA BAHIA, 2017: 15).

Segundo Louro (2008), os temas de gênero e sexualidade são construídos na sociedade simultaneamente por inúmeras práticas que são direcionadas para a juventude por meio de várias instâncias sociais e culturais: a escola, a família, a igreja, entre outros espaços. Isso possibilita múltiplos atravessamentos dessas questões nas vidas desses jovens, que muitas vezes acontecem de forma normativa e até coercitiva.

Essas "pedagogias culturais", como Louro (2008: 18) as chama, implementam normas de conduta em relação às questões de gênero e sexualidade e se firmam dentro de espaços que Foucault (2008b: 121) chama de "instituições de sequestro". São espaços (fábricas, hospitais, escolas, entre outros) regidos historicamente por uma disciplina que atinge os corpos dos indivíduos, normatizando-os de acordo com o modelo desejado. Dentre os aspectos do corpo que são alvos de normatização na escola - espaço pelo qual toda juventude é e/ou deveria ser cooptada - está, principalmente, a sexualidade. Para o autor (FOUCAULT, 1999), o sexo fixou-se no pano de fundo dessa regulação do corpo, uma vez que, a partir disso, ele foi também colocado no centro de uma disputa política que se desenvolveu por meio de dois eixos:

De um lado, faz parte das disciplinas do corpo: adestramento, intensificação e distribuição das forças, ajustamento e economia das energias. Do outro, o sexo 
pertence à regulação das populações, por todos os efeitos globais que induz. Inserese, simultaneamente, nos dois registros; dá lugar a vigilâncias infinitesimais, a controles constantes, a ordenações espaciais de extrema meticulosidade, a exames médicos ou psicológicos infinitos, a todo um micropoder sobre o corpo; mas, também, dá margem a medidas maciças, a estimativas estatísticas, a intervenções que visam todo o corpo social ou grupos tomados globalmente. O sexo é acesso, ao mesmo tempo, à vida do corpo e à vida da espécie. (FOUCAULT, 1999: 136-137).

Assim, ao passo em que a juventude é capturada pela sexualidade, essa se torna uma tecnologia de governo dessa população, com a pretensão de regular e regulamentar as práticas e modos de subjetivação desses indivíduos e desse grupo social por meio da disposição normativa de como essa sexualidade deve se dar, de como esses sujeitos, a partir do momento em que se tornam seres sexuados, devem existir.

Isso se dá, especialmente, em dois espaços: na família e na escola. Pois são esses os espaços de convivência compulsória para os jovens (de até 18 anos) no Brasil, de acordo com as leis que os regulamentam. Nesse sentido, nos espaços em que esses jovens são governados (na família e na escola), o controle de sua(s) sexualidade(s) se torna uma "tecnologia de governo" por essas instituições, já que para elas a sexualidade funciona como um marcador desses sujeitos enquanto "jovens" e, portanto, algo que deve ser positivamente investido de investigação, controle e regulação.

Um exemplo disso são as políticas de educação clássicas, que ensinam educação sexual nas escolas de forma biologicista, reduzindo a sexualidade à reprodução da espécie, atendo-se somente a questões como uso de métodos contraceptivos e prevenção de DSTs (Doenças Sexualmente Transmissíveis), muito embora a discussão da sexualidade por um viés mais amplo, que inclua o respeito à diversidade sexual, seja pauta dos Parâmetros Curriculares Nacionais - PCNs -, dispostos pelo Ministério da Educação - MEC -, desde o final da década de 90, teoricamente.

Sabemos que isto só será alcançado se oferecermos à criança brasileira pleno acesso aos recursos culturais relevantes para a conquista de sua cidadania. Tais recursos incluem tanto os domínios do saber tradicionalmente presentes no trabalho escolar quanto as preocupações contemporâneas com o meio ambiente, com a saúde, com a sexualidade e com as questões éticas relativas à igualdade de direitos, à dignidade do ser humano e à solidariedade (BRASIL, 1997, p.4).

Essa preocupação da escola em relação às questões pertinentes da contemporaneidade se dá porque a escola também é um espaço de formação de cidadãos de acordo com a 
Constituição Federal (BRASIL, 1988). E, dessa forma, faz-se imprescindível que questões que tocam a cidadania desses sujeitos sejam abordadas nesse espaço. E é a partir disso que podemos pensar na juventude LGBT, ainda muito invisibilizada pelo padrão heteronormativo reproduzido na escola. Nela, "A posição "normal” é, de algum modo, onipresente, sempre presumida, e isso a torna, paradoxalmente, invisível. Não é preciso mencioná-la. Marcadas serão as identidades que dela diferirem" (LOURO, 2008: 22).

Além disso, nos arredores do Golpe de 2016 houve uma ênfase na criação e/ou investimento em Projetos de Lei que ressaltam a importância tanto de um dado tipo de família ${ }^{4}$, quanto de uma dada forma de atuação da escola na vida dxs jovens, seja por uma estrutura específica ou por um modo também específico de legitimidade dessa família - e dessa escola - nas esferas pública e privada da vida. Apresentemos dois exemplos:

A retomada do trâmite do Estatuto da Família (PL 6583/2013) (CÂMARA DOS DEPUTADOS, 2013) em 2016, que estabelece diretrizes sobre os direitos de um único legítimo modo de constituir família como sendo o modelo heteronormativo; ou seja, composto por um casal heterossexual (formado por um homem e uma mulher) com filhos. Além disso, o PL também ressalta a importância da escola no que toca à transmissão dos valores dessa família, como mostra o Artigo 12 (CÂMARA DOS DEPUTADOS, 2015: 4): "As escolas deverão formular e implantar medidas de valorização da família no ambiente escolar, com a divulgação anual de relatório que especifique a relação dos escolares com as suas famílias".

O outro exemplo é referente à Lei Harfouche (PL 219/2015) (CÂMARA DOS DEPUTADOS, 2015), que tramita no Mato Grosso do Sul, cuja proposta é implementar atividades educativas reparadoras dos danos, que se assemelha muito à "obrigação de reparar o dano" - já presente enquanto medida socioeducativa pelo Estatuto da Criança e do Adolescente (1990: 73) - para jovens dentro do ambiente escolar (CÂMARA DOS DEPUTADOS, 2015). Sérgio Harfouche, criador do PL, - durante audiência pública realizada na Câmara Municipal de Dourados - MS (2017), relata que o projeto tem como objetivo a

\footnotetext{
${ }^{4}$ Com a repetição da frase "Eu defendo a Família Tradicional Brasileira" - proferida em massa não apenas nas eleições presidenciais de 2014 por candidatos conservadores, mas também como justificativa durante os votos a favor do Impeachment/Golpe de 2016 -, o termo "Família Tradicional Brasileira" ganhou ênfase em termos de publicidade, seja em outdoors, adesivos de carros e demais manifestações de apoio.
} 
participação da família nas deliberações da escola, uma vez que o cumprimento ou não da atividade reparadora de dano pelx jovem deveria passar pelo aval dos pais.

Além disso, ele menciona, durante tal Audiência Pública, que "Temos que deixar de lado questões ideológicas, partidárias, o que quer que seja. Temos que olhar isso com olhos de pai e mãe" (HARFOUCHE, 2017, s/p), ao justificar a importância de trazer a participação da família à escola, já que essa seria a única forma de se recuperar o respeito à autoridade, já que, "todos nós dependemos de disciplina" (HARFOUCHE, 2017, s/p).

Em ambos os projetos - cada um com seu foco de intervenção - percebemos atravessar um tipo de discurso que se manifesta no destaque dado a um tipo de família (heteronormativa, "tradicional") e à relação dessa com o ambiente escolar, como se os problemas presentes tanto na esfera da família quanto da escola demandassem uma articulação disciplinar entre as duas que, necessariamente, resvala na juventude enquanto foco de intervenção das mesmas. Assim, seja pela dissidência sexual, pela indisciplina ou por qualquer outra manifestação que coloque em questão os corpos dessa juventude em relação com as hierarquias presentes tanto no ambiente escolar quanto no familiar, a juventude se torna um foco de intervenções normalizadoras dessas esferas.

Temos então o encontro entre discursos que, no contexto atual, misturam escola e família como instituições de regulação da juventude, colocando em funcionamento um esquema que intensifica o governo da sexualidade quanto se atrela a um modelo "normal" de funcionamento da mesma: escola + família = tecnologia de governo da sexualidade .

\section{O PL “Escola sem partido" e suas conexões discursivas}

É a partir dessas relações que vemos emergir o PL "Escola sem partido" em diversos contextos. Para contextualizar a sua abrangência, é importante situar que ele advém de um movimento de capilaridade nacional chamado "Movimento Escola sem Partido" - MESP, que existe desde 2003 no Brasil e foi criado pelo advogado e procurador Miguel Nagib, cuja finalidade é promover uma educação com "neutralidade" (NAGIB, 2003). Para isso, ele propõe a proibição de discussões que envolvam política, gênero, sexualidade e religião nas escolas, afirmando que isso faz com que os professores doutrinem os alunos com as suas perspectivas ideológicas, com a justificativa de que tais temas não são da alçada da escola, nem do professor, cuja função, nesse sentido, é apenas transmitir conhecimento. 
Tal movimento deu origem a diversos Projetos de Lei em âmbito municipal, estadual e ao Projeto de Lei - PL - 867/2015, que é o PL que está tramitando a nível nacional, cujo objetivo é estabelecer na Lei de Diretrizes e Bases da Educação Nacional - LDB - o Programa Escola sem Partido. No senado quem fez a proposta foi o deputado Izalci (PSDBDF).

Em Campo Grande - MS, ele foi proposto inicialmente em 2014 pelo Vereador Alceu Bueno (sem partido), que renunciou ao cargo ao ser acusado de exploração sexual de adolescentes $^{5}$, de acordo com matéria veiculada pelo jornal Capital News (2016), o que o fez renunciar ao cargo e, consequentemente, ao Projeto de Lei.

Em 2016, o médico e vereador Paulo Siufi (PMDB) ${ }^{6}$ retomou o PL, que foi aprovado em regime de urgência pela Câmara Municipal, como apenas dois votos contrários, o do vereador Eduardo Romero (REDE Sustentabilidade) e da vereadora Luiza Ribeiro (PPS), cujos nomes costumam aparecer associados contrariamente - em comparação ao funcionamento de bloco em que as decisões na Câmara Municipal de Campo Grande costumam funcionar - no tocante às decisões que colocam em cheque a educação e o respeito às minorias (mulheres, negrxs, pessoas LGBT).

Em depoimento divulgado nas redes sociais, Eduardo Romero (CAPITAL NEWS, 2016b, s/p) justificou o seu voto contrário à aprovação do projeto, dizendo que "O professor tem a liberdade de ensinar assegurado na Constituição Federal. A proposta vai na contramão da educação crítica e reflexiva que buscamos e reforça o preconceito as diferenças culturais, sociais e políticas".

Tal acontecimento resultou na revolta de pessoas de diferentes áreas, envolvidas direta ou indiretamente com a educação, que se uniram na campanha "Ensinar é um ato Político", encampada por Grupos de Estudos, Diretórios Centrais de Estudantes - DCEs de universidades da capital, por professores, alunos, movimentos sociais e outras organizações. A campanha se articulou e foi até à Câmara Municipal com cartazes, manifestando-se contra a aprovação em regime de urgência. Dentre as mensagens e as vozes da manifestação, estava a

\footnotetext{
${ }^{5}$ Para mais detalhes, consultar a reportagem: https://www.campograndenews.com.br/lado-b/comportamento-2308-2011-08/debate-alerta-para-o-que-ninguem-esta-vendo-no-projeto-escola-sem-partido

${ }^{6}$ É importante destacar que Paulo Siufi, atual deputado estadual do Mato Grosso do Sul, foi acusado pela mesma operação (Operação coffe break do Ministério Público - MS) que resultou na cassação do mandato de Alcides Bernal, por corrupção passiva. Porém o processo foi suspenso porque um dos desembargadores a quem compete a análise do caso pediu mais tempo para realizar tal ação.
} 
frase "Veta Bernal!" 7 fruto de campanha organizada pela Federação dos Trabalhadores em Educação do Mato Grosso do Sul - FETEMS - (2016) -. Além disso, as campanhas também divulgaram cartazes com a mensagem "Educar é um ato político", alegando que tal projeto tiraria do professor uma função que é constitucionalmente embasada, que é a função de educar e formar cidadãos (FETEMS, 2016).

Depois disso, com toda a visibilidade adquirida pelas manifestações e campanhas, o PL "Escola sem partido" foi considerado inconstitucional e vetado pelo então prefeito de Campo Grande, Alcides Bernal, de acordo com matéria veiculada pelo jornal Midiamax (2016).

Porém, alguns meses após esse acontecimento o PL Escola sem partido (PL 8.519/17) foi reformulado e apresentado em uma nova versão - indêntica à anterior, com irrisórias modificações- à Câmara Municipal de Campo Grande - MS pelo vereador Vinícius Siqueira (DEM) e se encontra em tramitação. De acordo com matéria veiculada pelo jornal Campo Grande News (2017), apesar de a proposta ter sido travada pelo Supremo Tribunal Federal STF -, o vereador Vinícius Siqueira (DEM), retomou, com algumas alterações que, segundo ele, tornariam o PL constitucional, e esse está tramitando novamente na Câmara Municipal de Campo Grande - MS. ${ }^{8}$

Em relação à proposta do Projeto de Lei, cabe pensarmos na sua efetivação enquanto encontro dos discursos que o PL comporta em seu conteúdo e a sua emergência em um contexto político que busca atender a uma proposta de silenciamento da educação, questão que será melhor explanada adiante.

O projeto declara, em seu artigo $2^{\circ}$, que:

O Poder Público não se imiscuirá na orientação sexual dos alunos nem permitirá qualquer prática capaz de comprometer, precipitar ou direcionar o natural amadurecimento e desenvolvimento de sua personalidade, em harmonia com a respectiva identidade biológica de sexo, sendo vedada, especialmente, a aplicação dos postulados da teoria ou ideologia de gênero. (CAMARA DOS DEPUTADOS, 2016, s/p).

\footnotetext{
${ }^{7}$ Alcides Bernal foi o prefeito do município de Campo Grande - MS, durante o período de 2015-2016, tendo seu mandato cassado após nove acusações de crimes políticos e administrativos realizadas por vereadores da oposição.

${ }^{8}$ Atualmente, o mesmo PL tramita na Câmara Municipal, porém sob a representação (e apresentação) de Mara Caseiro (PSDB). No dia 23 de maio de 2018, o PL foi discutido na Assembleia Legislativa gerando debates entre os defensores e os que consideram o PL retrógrado, como é o caso do deputado e professor Pedro Kemp (PT). Em função disso, Mara Caseiro cancelou a audiência.
} 
É possível compreender, a partir desse artigo, uma série de questões, como o seu teor biologicista, uma vez que o artigo faz menção à suposta naturalidade do desenvolvimento sexual, pautada no que é posto como uma "identidade biológica" (CÂMARA DOS DEPUTADOS, 2016, s/p), exaltando o que Foucault (1999) discorreu sobre a verdade do sexo, a relação entre saber e poder em torno da temática da sexualidade com $o$ estabelecimento do que ele chamou de "discurso científico sobre o sexo" ou "scientia sexualis" (FOUCAULT, 1999, p.55), que se vinculou intimamente ao saber médico para docilizar os comportamentos sexuais, visando, dentre outras coisas, preservar a espécie em sua saúde e moralidade. De forma que essas duas instâncias foram se atravessando: a saúde se pautando na biomedicina para legitimar discursos enviesados por questões morais e a moralidade se travestindo de discurso científico, o que foi tornando esses territórios cada vez mais um único território quando se tratava do que era/é considerado como dissidente à norma (hetero)sexual.

Essa docilização, para Foucault (1999), dava-se a partir de práticas de produção de verdade que passavam, também, por práticas que objetivavam mascarar o próprio sexo, silenciá-lo. Assim, podemos dizer que o silêncio aparece como propulsor de um discurso que, para fortalecer a soberania de uma dada forma de sexualidade como normal, como padrão, mascara, silencia, outras que emergem como transgressoras e que são, então, tiradas de circulação no ambiente escolar a partir de um dispositivo amordaçador, que, neste caso, é o Projeto de Lei citado.

Podemos dizer que esse silêncio também aparece como um discurso (FOUCAULT, 1999), pois não falar sobre o assunto é permitir que a violência aconteça e, ainda que de forma silenciosa, essa conivência se torna um discurso a partir do momento em que se percebe que certas práticas - como a violência, neste contexto - acontecem, especialmente, diante de um silenciamento que denota a supremacia de um discurso. Ou seja, o silêncio se torna o próprio discurso e a inação diante da violência, a própria violência.

Retomamos então o caso do menino gay de 16 anos que foi morto no Ceará durante o que as autoridades nomearam de "um conflito familiar" (GRUPO GAY DA BAHIA, 2017: 15), pois é em casos como esse que o discurso do silêncio fala mais alto do que a proteção que deveria haver por parte do Estado - prevista inclusive, segundo o ECA, para casos de 
violência intrafamiliar -. E é também em casos como esse que se há de questionar o papel da escola, por meio dos discursos que ela (re)produz, como espaço de formação de cidadania, no que toca à proteção e ao silenciamento que os reverberamentos desses discursos produzem sobre essxs jovens, especialmente sobre xs que estão sendo violentados pela família.

Para Foucault, nada há por trás das cortinas, nem sob o chão que pisamos. Há enunciados e relações, que o próprio discurso põe em funcionamento. Analisar o discurso seria dar conta exatamente disso: de relações históricas, de práticas muito concretas, que estão vivas nos discursos (FISCHER, 2001, p.198-199).

Esses discursos, como descrito acima, de acordo com Fischer (2001), aparecem no âmbito da educação a partir de práticas discursivas e não discursivas, uma vez que o discurso é, para além do que se diz, o que reverbera do que é dito, incluindo assim as práticas que são produzidas com e a partir desses dizeres.

Pensar o silêncio enquanto um discurso, neste caso, é denotar a existência de uma racionalidade normal, porque pertencente à norma, e constituída por saberes, práticas e conjugada a relações de poder diversas, que produz o silêncio como dispositivo para a manutenção do seu discurso enquanto hegemônico, enquanto único discurso legítimo. Pois ao silenciar aquilo que dela difere, é anulada também a possibilidade da coexistência de outras formas de viver, de outras vidas.

Eis aqui o teor amordaçador - porque silenciador e violento - do PL em questão, já que a sua proposta consiste na proibição da abordagem de questões de gênero e sexualidade para além da (hetero)normativa, que é pelo projeto colocada como condizente a um suposto "natural desenvolvimento" (CÂMARA DOS DEPUTADOS, 2016, s/p) desses jovens, ou seja, ilegitimando outras formas de vivência da sexualidade por uma suposta impossibilidade - embasada em um desenvolvimento tido "normal" - de que essas possam coexistir no ambiente escolar com as outras.

Além disso, não são apenas xs alunxs que são silenciados, pois o Projeto pretende que temáticas relacionadas à política ou à "ideologia de gênero" (CÂMARA DOS DEPUTADOS, 2016, s/p) - termo usado pejorativamente para se referir aos estudos mais recentes que discutem questões de gênero e sexualidade vinculadas aos contextos sociais e políticos sejam proibidas de circularem no ambiente escolar, o que faz com que os professores e 
funcionários também sejam silenciados diante de situações em que esses assuntos vierem a emergir.

E, para justificar tal silenciamento, o projeto declara que esses assuntos devem ser abordados em casa, pela família, e não pela escola, uma vez que a intenção dessa não é interferir nos ensinamentos e na moral que é transmitida por aquela. Ora, aqui se coloca uma transferência nítida da função de formação de cidadania, que antes era também do Estado, da Escola, para a Família, para o ambiente privado.

Quando o Projeto de lei (CÂMARA DOS DEPUTADOS, 2016) declara que a escola deverá disponibilizar para os pais ou responsáveis o material a ser ministrado nas aulas e, caso esse material seja de cunho religioso, moral ou ideológico, a escola precisará do aval dos pais para que o conteúdo seja compartilhado com os alunos, podemos dizer que esse projeto de lei desloca, por meio de um jogo sutil entre questões que envolvem política, religião e o que é colocado como "ideologia", a função que foi constitucionalmente conquistada pela educação, que coloca a escola como espaço de formação de cidadania, apenas à família. E, ainda, esse movimento é feito num contexto em que essa família é, como foi trazido pelo Grupo Gay da Bahia (2017) no início deste artigo, expressivamente presente nos rankings de violência contra a juventude LGBT.

\section{A interdição à cidadania da Juventude LGBT como desdobramento do Golpe}

Ao golpe parlamentar ocorrido em 2016 à presidência de Dilma Rousseff podemos ligar vários acontecimentos que, de maneira micropolítica (GUATTARRI; ROLNIK, 1996), articularam-se a ponto de discursivamente terem estruturado (e continuarem estruturando) o golpe enquanto acontecimento sob a forma "legítima" do impeachment ao mandato da presidenta.

Um dos desdobramentos do Golpe de 2016 ocorreu durante o primeiro mandato da presidenta Dilma, em 2011, a partir de seu inicial posicionamento sobre o "kit contra a homofobia", material disposto pelo MEC (Ministério de Educação e Cultura) para ser apresentado nas escolas como forma de combate à violência e discriminação contra pessoas LGBT no ambiente escolar. Dilma aprovou o projeto referente a esse material, porém, após manifestações polêmicas de diversos grupos conservadores que apelidaram o material de "kit 
gay", afirmando que o mesmo servia para influenciar crianças a se tornarem homossexuais - e relacionando tal aprovação à por eles suposta conduta homossexual da presidenta -, essa vetou a sua circulação, resultando não apenas na proibição do material nas escolas, como também na reiteração - feita durante a campanha que precedeu o seu segundo mandato - de que não aprovaria projetos estimulando a homossexualidade ${ }^{9}$.

Em relação à postura controversa de Dilma - que desde o primeiro mandato demonstrou preocupação com pautas voltadas para questões de gênero e sexualidade -, podese dizer que essa mudou de perspectiva em resposta aos ataques conservadores direcionados a ela. Porém, o fato de a emergência do MESP (Movimento Escola sem Partido) ter ocorrido em 2016 - com a capilarização de projetos de lei municipais simultâneos ao que tramita no Senado, a nível nacional - mostra uma articulação discursiva entre o golpe às pautas de gênero e sexualidade (e, consequentemente, à cidadania LGBT e o golpe materializado ao segundo mandato da presidenta, com o impeachment que ocorreu no mesmo ano.

A mudança de postura de Dilma em relação às pautas LGBT só fortaleceu discursivamente a fidedignidade dos ataques à ela e à população LGBT direcionados, como se tal posicionamento controverso tivesse sido um "tiro pela culatra". Em outras palavras, o golpe parlamentar de 2016 não está descolado do golpe orquestrado à cidadania LGBT promovida pelo discurso do MESP. Assim, dizer que a interdição à cidadania LGBT é um desdobramento do golpe implica em tomá-la como parte de um processo de desmonte da democracia, desmonte cuja capilaridade abarca, por exemplo, a proibição de se falar sobre sexualidade nas escolas e, consequentemente, a proibição da existência discursiva de sexualidades dissidentes (como as identidades LGBT) nesse espaço que, teoricamente, é democrático.

Segundo uma Professora da Faculdade de Educação da UFMG (Universidade Federal de Minas Gerais), cuja fala aparece no documentário "PL 274 Escola Sem Partido" disponibilizado na plataforma do Youtube pelo Fórum da Juventude da Grande BH (2017):

Primeiro eu penso que é importante que as pessoas consigam entender o que é a função do professor da educação básica, professor que trabalha com criança,

\footnotetext{
${ }^{9}$ Claramente, a presidenta ficou impactada com os efeitos discursivos conservadores - já orquestrados desde então - contra o seu mandato, optando por uma postura politicamente estratégica em relação à sua reeleição. Para mais informações, acessar: http://g1.globo.com/educacao/noticia/2011/05/governo-nao-fara-propaganda-deopcao-sexual-diz-dilma-sobre-kit.html
} 
adolescente, com jovem, com adulto e com idoso. E a LDB, que é a Lei de diretrizes e Bases da Educação Nacional, ela diz tudo que o professor tem que fazer e lá no artigo 13 ela diz que o professor tem que zelar pela aprendizagem dos estudantes e diz também que ele tem que cuidar para aqueles que estão tendo um rendimento mais baixo consigam aprender. E aí eu fico pensando em situações de vida, situações de vivência, de dia-a-dia que eu ouvi de alguns estudantes durante esses 29 anos de idade e que se eu não pudesse ter participado delas como educadora, se eu não pudesse ter participado delas tentando, de alguma forma, fazer com que as situações vividas por eles fossem denunciadas, fossem resolvidas, eu não sei como é que eles aprenderiam, porque alguém que está sofrendo não aprende. (FÓRUM DA JUVENTUDE DA GRANDE BH, 2017, s/p).

Ou seja, a violência ocorre também em grande medida por conhecidos e no contexto familiar, ambientes esses em que o jovem também deveria ser protegido, em termos legais. De acordo com o Estatuto da Criança e do Adolescente (1990), as medidas protetivas devem ser aplicadas às crianças e adolescentes quando esses tiverem seus direitos violados pela sociedade e pelo Estado, em suas ações ou omissões, pelos pais ou responsáveis, por falta, omissão ou algum tipo de abuso ou em razão de sua conduta.

A dificuldade no processo de "saída do armário" - revelação de uma orientação que difere da heterossexualidade e identidade cisgênero- pela juventude LGBT, de acordo com Perucchi; Brandão e Vieira (2014, p. 70), está relacionada à dificuldade que essa enunciação causa à convivência dxs jovens com seus familiares, que piora, na maioria das vezes. "Assim, mesmo pessoas que se assumem homossexuais, são poucas as que não se encontram no armário com alguém que seja de alguma forma importante para elas" (PERUCCHI; BRANDÃO \& VIEIRA, 2014, p. 70).

Dessa forma, ocorre uma hegemonia da (in)visibilização da juventude LGBT, que não pode vivenciar sua sexualidade/identidade de gênero socialmente, pois isso esbarra nas questões discutidas acima - uma sociedade majoritariamente lgbtfóbica -. Fato que se expressa fortemente na escola e na família, que são não apenas os ambientes de principal convivência social dxs jovens, como também os espaços que tutelam essxs sujeitxs e, por extensão, produzem discursos (em silêncio ou não) de como suas sexualidades podem ou não existir.

Cabe aqui refletirmos em como Projeto de Lei "Escola sem Partido" ajuda a tecer essa rede de (des)proteção à juventude ao colocar-se como um “dispositivo" (AGAMBEN, 2009, 


\section{Nanduty}

ISSN:2317-8590

p.29) de silenciamento da educação e concomitante fortalecimento do poder familiar, o que nos parece não ser uma característica exlusiva do PL em questão, mas, antes, um dispositivo político que, enquanto discurso, atravessa outras determinações legais, como foi trazido em relação ao Estatuto da Família e à Lei de Harfouche, por exemplo.

Agamben (2009) entende o dispositivo, a partir de uma genealogia por ele feita sobre o aparecimento desse termo nas obras de Foucault e em outros contextos históricos, como uma articulação entre discursos, práticas, medidas, construções, instituições e etc, formando uma rede estrategicamente composta por relações de saber e relações de poder articuladas entre si.

Quando se percebe expressivamente uma ideia - a valorização da Família Tradicional Brasileira como hegemonicamente legítima e, inclusive, silenciadora das outras formas possíveis - atravessando diversos Projetos de Lei e, ainda, capilarizando-se em diversos municípios, é preciso questionar o que é que, num contexto macropolítico, faz com que tais movimentos ganhem força e visibilidade. Nesse sentido, pode-se dizer que há uma articulação maior envolvendo tais acontecimentos e que, no contexto atual, ela vem ocupando cada vez mais espaço. Parece-nos que a ideia de uma "ideologia de gênero" - que será abordada adiante - coloca-se enquanto eixo central da engrenagem silenciadora e violenta em relação à juventude LGBT.

\section{O terror da "ideologia de gênero"}

Em palestra conferida na Universidade Federal do Mato Grosso do Sul - UFMS - em julho deste ano, Junqueira (2017) trouxe uma abordagem histórica do uso do termo "ideologia de gênero", que é utilizado também pelo movimento Escola sem partido e pelo PL (CÂMARA DOS DEPUTADOS, 2016), que é fruto desse movimento e se encontra em tramitação na Câmara Municipal de Campo Grande.

O termo surgiu, de acordo com Junqueira (2017), na Europa, a partir da iniciativa de grupos católicos como a Opus Dei, associações pró-vida (contra o aborto) e outros grupos neofundamentalistas, como reação a movimentos feministas e LGBT, a partir da presunção daqueles de que esses objetivam acabar com os gêneros masculino e feminino com suas "teorias" sobre o gênero. 
Junqueira (2017) caracteriza esse movimento como um "metadiscurso", ou seja, um discurso cujo conteúdo é essencialmente de uma oposição a um dito discurso. Ou, nas palavras do autor "eles estão fazendo a ofensiva e nos acusam de fazer a ofensiva". Por isso o uso do terror em relação aos estudos de gênero e sexualidade, para que os estudos, em si, não sejam visibilizados, apenas a névoa de horror que foi, propositadamente, formada em torno deles.

Foucault (2001, p.15) chamou de "ubuesco" o discurso que transita entre uma monstruosidade e uma comicidade e que, por conta disso, não deixa claro o seu teor de seriedade, de realidade, sendo, ele mesmo, o próprio absurdo que transparece.

O terror ubuesco, a soberania grotesca ou, em termos mais austeros, a maximização dos efeitos do poder a partir da desqualificação de quem os produz. Isso, creio eu, não é um acidente na história do poder, não é uma falha mecânica. Parece-me que é urna das engrenagens que são parte inerente dos mecanismos do poder. $\mathrm{O}$ poder político, pelo menos em certas sociedades, em todo caso na nossa, pode-se se atribuir, e efetivamente se atribuiu, a possibilidade de transmitir seus efeitos, e muito mais que isso, de encontrar a origem dos seus efeitos nurn canto que é manifestamente, explicitamente, voluntariamente desqualificado pelo odioso, pelo infame ou pelo ridículo (FOUCAULT, 2001, p.15).

Durante a fala de Junqueira (2017), as reações do público à apresentação do metadiscurso da "ideologia de gênero" se deram concomitantemente com espanto e riso. Esse absurdo que choca e faz rir não os faz à toa. Há algo que, segundo o autor, sustenta essa reação que chamamos aqui de "ubuesca" (FOUCAULT, 2001, p.15) e, neste caso, esse algo se dá num encontro entre os discursos biomédico e religioso moral.

Ainda de acordo com Junqueira (2017), na Europa esses movimentos apresentam uma base mais voltada para um suposto discurso científico, sendo apoiados por associações de pediatria e vinculando a discussão diretamente aos discursos biomédicos sobre desenvolvimento infantil, enquanto na América Latina eles apresentam um forte cunho religioso e são, inclusive, apoiados por líderes religiosos ou, em algum momento, apresentam o atravessamento da questão religiosa, para além do discurso de cunho biológico.

Não coincidentemente, em Campo Grande - MS, como foi anteriormente exposto, o projeto foi encampado em 2016 pelo vereador - que atualmente é deputado estadual - Paulo 
Siufi (PMDB), que é também evangélico e médico pediatra. Além disso, Paulo Siufi também se posicionou contra a distribuição do material disponibilizado pelo programa "Brasil sem homofobia" em 2010, material que seria direcionado às escolas públicas como parte do material didático, com o intuito de abordar questões referentes às temáticas de gênero e sexualidade a partir de um viés pedagógico, trazendo questões como a homossexualidade para serem abordadas dentro do ambiente escolar, de forma a trazer a pauta da prevenção à homofobia para dentro das escolas. O material não só foi apelidado como "kit gay", como também teve a sua circulação impedida pela Presidenta Dilma após polêmica.

Paulo Siufi declarou, em relação à circulação do material, de acordo com matéria divulgada pelo jornal Campo Grande News (2010):

\footnotetext{
"Imaturas, crianças vão ser colocadas no furacão da sexualidade sendo estimuladas a pensarem na homossexualidade. Eu não acredito que as famílias devem ser submetidas a essa agressão". (CAMPO GRANDE NEWS, 2010, s/p)
}

Percebe-se, então, que o PL "Escola sem partido" tem uma característica rizomática (DELEUZE \& GUATTARI, 2010), ou seja, capilarizada, conectada com outras práticas, ideias e discursos que já circulavam antes do Projeto de Lei "Escola sem partido" ser formalizado e apresentado à Câmara Municipal. Isso faz com que os discursos presentes no PL circulem para além do próprio projeto, de forma que se pode afirmar, inclusive, que ele vigora mesmo sem ter sido de fato legitimado, por um mecanismo que Agamben (2004, p.58) chamaria de "força-de-lei", já que medidas como a trazida acima foram tomadas. Para Agamben (2004) medidas com força-de-lei podem ser decretos, disposições e ações que, apesar de não serem leis, ou de não estarem legitimadas como tais, adquirem em seu discurso uma força semelhante à força de lei e isso faz com que essas medidas tenham peso e vigorem, especialmente quando as medidas que deveriam estar vigorando têm seus discursos enfraquecidos ou desconsiderados.

Seffner (2016) coloca em pauta o movimento do MESP dentro do que ele chama de um "pânico moral" que há em torno desses discursos envolvendo educação, gênero e sexualidade atualmente. Para o autor, antigamente as questões de gênero e sexualidade eram apenas um adorno à educação, não tomavam nenhuma centralidade nos debates e decisões, eram apenas uma questão de requinte. Atualmente, essas questões são de suma importância e 
têm tomado uma centralidade que coloca a educação como "terreno de disputa" (SEFFNER, 2016, p.1).

O autor também traz à tona as declarações de votos no processo de impeachment da presidenta Dilma, em 2016, já que no momento do voto muitos parlamentares utilizavam como justificativa o fato de serem contra a "ideologia de gênero" para serem favoráveis ao Impeachement da presidenta, evidenciando a relação - trazida anteriormente - entre a figura e os discursos da presidenta e a necessidade de silenciamento das questões de gênero e sexualidade pelos mesmos.

Seffner (2016) também problematiza a apropriação do termo feita pelo PL "Escola sem Partido", já que essa expressão aposta num jogo discursivo ao colocar o silenciamento da sexualidade e do gênero na escola como uma forma de evidenciar a necessidade de apartidarismo da mesma. Como se abordar tais temas fosse tomar um partido, colocando, automaticamente, as questões de gênero e sexualidade como partidárias, ideológicas, dignas de serem silenciadas sob a justificativa de uma dada neutralidade por parte da escola.

Isso leva a cogitar sobre o que Sefnner (2017) disse em um fórum de discussão do evento internacional 13 Mundos de Mulheres e Fazendo Gênero 11, "Se durante a ditadura era o comunismo o terror da população, atualmente quem ocupa esse lugar é a ideologia de gênero". Com isso, ele acrescenta que atualmente há um pânico moral no que tange às questões de gênero e sexualidade, ou seja, são questões que acionam um medo social, como se tais questões denotassem um perigo eminente, especialmente quando nos referimos à juventude e à educação. Contudo, para o autor, é justamente por essa razão que reside nessa questão uma concomitante potencialidade de ação, de resistência, uma vez que, para ele, "assim como mora em nós a capacidade de apanhar, mora também a capacidade de assustar" (SEFFNER, 2017).

Em outras palavras, esse locus de terror no qual os estudos de gênero e sexualidade foram colocados também é o que deu a essas questões um teor de importância política, de relevância e foco de atuação. Assim sendo, mora nessa situação também a capacidade de resistência diante do cenário que está sendo posto, ou seja, é essa condição de destaque que, ao implicar as questões de gênero e sexualidade - por mais negativado que seja esse destaque 
- faz com que essas questões ocupem um lugar de relevância e possibilitem que aqueles que são violentados resistam.

Segundo Rodrigo Ednilson de Jesus, professor da Faculdade de Educação da UFMG (Universidade Federal de Minas Gerais) e Pró Reitor adjunto de assuntos estudantis na mesma instituição, cuja fala aparece no documentário "PL 274 Escola Sem Partido" disponibilizado na plataforma do Youtube pelo Fórum da Juventude da Grande BH (2017, s/p):

Esse projeto "Escola sem partido", da forma como ele vem sendo tramitado e se a gente ler com atenção, a gente vai perceber que não se trata da defesa de uma escola que não toma partido, mas se trata de uma crítica a escolas que tomam partido para determinadas causas. E a gente identifica que é uma crítica a escolas que tomam partido em causas de combate à discriminação de gênero, racial, de orientação sexual. É uma crítica a uma escola que toma partido em relação à desigualdade produzida pelo nosso sistema capitalista. Então, no meu ponto de vista, esse projeto é também um projeto de escola com partido, é mais uma defesa de uma escola que toma partido em prol do conservadorismo, da manutenção daquilo que já está, daquilo que já está colocado. Então é uma escola abertamente conservadora, mas que se esconde atrás de um discurso de neutralidade, de apartidarismo.

\section{CONSIDERAÇÕES FINAIS}

Entende-se, com essa reflexão, que a proposta de neutralidade do PL "Escola sem partido" não se concretiza como o seu próprio discurso tenta sustentar. Pois ao proibir a circulação, dentro do ambiente escolar, de temas cujas discussões importam para que certos grupos possam ter acesso a seus direitos e, assim, exercer a sua cidadania, o PL está tomando um partido e, mais do que isso, está tomando um partido que é excludente e que corrobora na legitimação de uma violência que já é regra na sociedade, que são as intolerâncias

\section{LGBTfóbicas.}

Nesse sentido, a aprovação do PL mencionado seria equivalente à legitimação de uma lógica que já existe e, mesmo não sendo legal, não estando na lei, opera interditando a cidadania da juventude LGBT, uma vez que já há - como foi mencionado anteriormente uma resistência social e que é refletida na escola em relação à abordagem de questões ligadas aos direitos da comunidade LGBT. 


\section{Nanduty}

ISSN:2317-8590

Cabe pensar essa proibição proposta pelo PL como um dispositivo de silenciamento, ou seja, como uma engrenagem do que chamamos de lógica da mordaça, que é a utilização do silêncio como um discurso.

Dito de outra forma, a partir das reflexões suscitadas neste trabalho, propõe-se que seja pensado, para além da relação entre a compulsoriedade do silêncio e a legitimação da violência, em como esse Projeto de Lei, enquanto discurso e enquanto dispositivo de articulação de variados discursos, como foi mostrado, estende a sua proposta também a um modelo de sociedade, um modelo de cidadão.

Segundo Foucault (1996, p.44), “Todo sistema de educação é uma maneira política de manter ou de modificar a apropriação dos discursos, com os saberes e os poderes que eles trazem consigo". A partir disso, pode-se perceber que tal proposta, que se entende como neutra dentro do espaço educacional e que o faz a partir da imposição do silêncio sobre algumas pautas e sobre algumas vidas, está chamando de neutralidade um posicionamento notoriamente direcionado, em termos ideológicos, atualmente. Especialmente, como foi dito, se considerarmos o percurso desses discursos e a situação da juventude LGBT nas escolas.

Portanto, com este trabalho, que é um discurso e que é político, porque implicado num contexto e cuja implicação é a sua própria realização, por si mesma, pretende-se problematizar não apenas os discursos que atravessam projetos como o PL 8.519/17, vulgo "Escola sem partido", como também pensar seus alcances, para além do papel e questionar os seus rumos. Pois, se "educar é um ato político", pesquisar e escrever sobre a educação, neste contexto, tem de ser uma ferramenta política, cujo sentido tem de ser o de quebrar o silêncio e de trazer consigo a possibilidade de novos caminhos.

\section{REFERÊNCIAS BIBLIOGRÁFICAS}

AGAMBEN, Giorgio. 2004. Estado de exceção: homo sacer II. São Paulo: Boitempo.

AGAMBEN, Giorgio. 2009. O que é contemporâneo? e outros ensaios. Chapecó - SC: Argos.

ASSOCIAÇÃO BRASILEIRA DE GAYS, LÉSBICAS, BISSEXUAIS, TRAVESTIS E TRANSEXUAIS. 2016. Pesquisa nacional sobre o ambiente educacional no Brasil 
2016: as experiências de jovens lésbicas, gays, bissexuais, travestis e transexuais em nossos ambientes educacionais.

BRASIL. 1988. Constituição da República Federativa do Brasil. Brasília - DF: 1988. Disponível

em: http://www.planalto.gov.br/ccivil_03/constituicao/constituicao.htmAcesso em: 16 de agosto de 2016.

BRASIL. 1990. Estatuto da Criança e do Adolescente. Brasília - DF.

BRASIL. 1997. Secretaria de Educação Fundamental. Parâmetros curriculares nacionais: introdução aos parâmetros curriculares nacionais / Secretaria de Educação Fundamental. - Brasília : MEC/SEF, 126p.

BRASIL. 2009. Promoção nacional da cidadania e dos Direitos Humanos de LGBT. Secretaria Especial dos Direitos Humanos da Presidência da República, Subsecretaria de Promoção e Defesa dos Direitos Humanos, Programa Brasil sem Homofobia. Brasília.

CÂMARA DOS DEPUTADOS. 2015. Projeto de lei $n^{\circ}$ 219/2015. Campo Grande - MS. Disponível em: http://www.camara.gov.br/proposicoesWeb/fichadetramitacao?idProposicao=94 6058 Acesso em 23 de outubro de 2016.

CÂMARA DOS DEPUTADOS. 2013. Projeto de lei $n^{\circ}$ 6583/13. Brasília - DF. Disponível em: http://www.camara.gov.br/proposicoesWeb/prop_mostrarintegra?codteor=1159761 Acesso em 23 de outubro de 2016

CÂMARA DOS DEPUTADOS. 2016. Projeto de Lei $n^{\circ}$ 8.242/16 de 28 de março de 2016. Campo Grande-MS. Disponível em: www.camara.gov.br/sileg/integras/1317168.pdf Acesso em 03 de agosto de 2016.

HARFOUCHE, Sérgio. 2017. Audiência pública "Restaurando possibilidades para fortalecer os papéis da comunidade escolar e da família para prevenir a evasão e a violência. Audiência Pública na Câmara Municipal de Dourados - MS, 18 de agosto de 2017. Mímeo

CAMPO GRANDE NEWS. 2016. Barrada na Justiça, vereador tenta de novo emplacar escola sem partido. Matéria publicada pelo jornal local Campo Grande News, no dia 10 de junho de 2017. Disponível em: https://www.campograndenews.com.br/politica/barrada-na-justica-vereador-tenta-denovo-emplacar-escola-sem-partido Acesso em: 16 de junho de 2017.

CAMPO GRANDE NEWS. 2010. Kit anti-homofobia do MEC causa problemas. Matéria publicada pelo jornal local Campo Grande News, no dia 15 de dezembro de 2010. 
Disponível em: https://www.campograndenews.com.br/politica/kit-anti-homofobiado-mec-causa-mais-uma-polemica-na-camara-da-capital Acesso em 06 de junho de 2017.

CAMPO GRANDE NEWS. 2017. Barrada na Justiça, vereador tenta de novo emplacar escola sem partido. Matéria publicada pelo jornal local Campo Grande News, no dia 10 de junho de 2017. Disponível em: https://www.campograndenews.com.br/politica/kit-anti-homofobia-do-mec-causamais-uma-polemica-na-camara-da-capital Acesso em: 06 de junho de 2017.

CAPITAL NEWS. 2016. Aprovado pela Câmara de Campo grande, projeto quer proibir professores de discutir política e sexualidade. Matéria publicada pelo jornal local Capital News, no dia 02 de abril de 2016. Disponível em: http://www.capitalnews.com.br/politica/aprovado-pela-camara-de-campo-grandeprojeto-quer-proibir-professores-de-discutir-politica-e-sexualidade/289791 Acesso em: 14 de abril de 2016.

CAPITAL NEWS. 2016. Em MS, projeto "Escola sem Partido" foi apresentado por exvereador condenado por exploração sexual. 2016b. Matéria publicada pelo jornal local Capital News, no dia 05 de abril de 2016. Disponível em: http://www.capitalnews.com.br/politica/em-ms-projeto-escola-sem-partido-foiapresentado-em-2014-por-ex-vereador-condenado-por-exploracao-sexual/289853 Acesso em: 13 de maio de 2016.

FETEMS. 2016. Todos contra a Lei da mordaça no ensino público. Texto publicado por Roberto Botareli (presidente da FETEMS). Disponível em: http://www.fetems.org.br/Utilidades/view/noticia:236/categoria:/search/menu:5/subme nu:35 Acesso em: 15 de julho de 2017.

FISCHER, Rosa Maria Bueno. 2001. Foucault e a análise do discurso em educação. Cadernos de Pesquisa, n. 114, novembro/ 2001 Cadernos de Pesquisa, n. 114, p. 197223.

FÓRUM DA JUVENTUDE DA GRANDE BH. 2017. PL 274 Escola Sem Partido. Vídeo disponibilizado no Youtube em 12 de agosto de 2017. Disponível em: https://www.youtube.com/watch?v=lfLevsqH5EE Acesso em 12 de agosto de 2017.

FOUCAULT, Michel. 1996. A ordem do discurso: aula inaugural no Collège de France. Pronunciada em 2 de dezembro de 1970. São Paulo: Editora Loyola.

FOUCAULT, Michel. 1999. História da sexualidade I: a vontade de saber. Rio de Janeiro: Editora Graal, $13^{\mathrm{a}}$ ed.

FOUCAULT, Michel. 2002. Os anormais: curso dado no Collège de France (1974-1975). São Paulo: Martins Fontes. 
FOUCAULT, Michel. 2008. Vigiar e punir: nascimento da prisão. Tradução de Raquel Ramalhete. 35. ed. Petrópolis: Vozes.

GRUPO GAY DA BAHIA. 2018. Pessoas LGBT mortas no Brasil: relatório 2017. Disponível em: https://homofobiamata.files.wordpress.com/2017/12/relatorio2081.pdf Acesso em 16 de julho de 2018

GUATTARI, Félix; ROLNIK, Suely. 1996. Micropolítica: Cartografias do desejo. Petrópolis - RJ: Editora Vozes, $4^{\mathrm{a}}$ ed.

JUNQUEIRA, Rogério Diniz. 2017. Palestra ministrada durante o evento Ciclo de debates (de)marcando diferenças no dia 12 de junlo de 2017. Campo Grande - MS: Universidade Federal do Mato Grosso do Sul - UFMS, Mímeo.

LOURO, Guacira Lopes. 2008. Gênero e Sexualidade: pedagogias contemporâneas. ProPosições, v. 19, n. 2 (56) - maio/ago.

MIDIAMAX. 2016. Bernal anuncia veto à 'Lei da Mordaça' e Siufi reage: 'sem base, derrubamos': proposta restringe conteúdo sobre sexo e política nas escolas. Matéria publicada pelo jornal local Midiamax em 04 de abril de 2016. Disponível em: http://www.midiamax.com.br/politica/bernal-anuncia-veto-lei-mordaca-siufi-reage-senao-tiver-base-derrubamos-296111 Acesso em: 05 de abril de 2016.

NAGIB, Miguel. 2013. Escola sem partido: educação sem doutrinação. Movimento social cujas informações estão disponíveis em: http://www.escolasempartido.org Acesso em: 20 de julho de 2016.

OLIVEIRA, Esmael Alves.; DUQUE, Tiago. 2016. Políticas do corpo, políticas da vida: uma análise sobre o Estatuto da Família no Brasil. Nanduty, v.4, n.5. pp. 132-153.

PERUCCHI, Juliana; BRANDÃO, Brune Coelho; VIEIRA Hortênsia Isabela dos Santos. 2014. Aspectos psicossociais da homofobia intrafamiliar e saúde de jovens lésbicas e gays. Universidade Federal de Juiz de Fora, Estudos de Psicologia, 19(1), janeiro a março 1-88.

SEFFNER, Fernando. 2016. Atravessamentos de gênero, sexualidade e educação: tempos difíceis e novas arenas políticas. Texto enviado como trabalho completo ao Eixo 18 (Gênero, sexualidade e educação) da XI Reunião Científica Regional da AMPED (AMPED SUL) que ocorreu em Curitiba - PR em julho de 2016. Disponível em: http://www.anpedsul2016.ufpr.br/wp-content/uploads/2015/11/Eixo-18G\%C3\%AAnero-Sexualidade-e-Educa\%C3\%A7\%C3\%A3o.pdf Acesso em 03 de Agosto de 2017.

SEFFNER, Fernando. 2017. Palestra ministrada durante o evento Ciclo de debates (de)marcando diferenças no dia 21 de junho de 2017. Campo Grande - MS: Universidade Federal do Mato Grosso do Sul - UFMS, Mímeo. 